3. Vermeersch P, Vercammen M, Holvoet A, Vande Broek I, Delforge M, Bossuyt X. Use of interval-specific likelihood ratios improves clinical interpretation of serum FLC results for the diagnosis of malignant plasma cell disorders. Clin Chim Acta. 2009;410:54-8.

4. Palladini G, Russo P, Bosoni T, Verga L, Sarais G, Lavatelli F, et al. Identification of amyloidogenic light chains requires the combination of serum-free light chains and with immunofixation of serum and urine. Clin Chem. 2009;55:499-504.

5. Palladini G, Dispenzieri A, Gertz MA, Kumar S, Wechalekar A, Hawkins PN, et al. New criteria for response to treatment in immunoglobulin light chain amyloidosis based on free light chain measurement and cardiac biomarkers: impact on survival outcomes. J Clin Oncol. 2012;30:4541-9.

6. Bradwell AR, Carr-Smith HD, Mead GP, Tang LX, Showell PJ, Drayson MT, et al. Highly sensitive, automated immunoassay for immunoglobulin free light chains in serum and urine. Clin Chem. 2001;47:673-80.
7. te Velthuis H, Knop I, Stam P, et al. N Latex FLC - new monoclonal high-performance assays for the determination of free light chain kappa and lambda. Clin Chem Lab Med. 2011;49:1323-32.

8. Carr-Smith HD, Jenner EL, Evans JAR, Harding SJ. Analytical issues of serum free light chain assays and the relative performance of polyclonal and monoclonal based reagents. Clin Chem Lab Med. 2016;54:997-1003.

9. Palladini G, Jaccard A, Milani P, et al. Circulating free light chain measurement in the diagnosis, prognostic assessment and evaluation of response of AL amyloidosis: comparison of Freelite and N latex FLC assays. Clin Chem Lab Med. 2017;55:1734-43.

10. Rajkumar SV, Dimopoulos MA, Palumbo A, Blade J, Merlini G, Mateos MV, et al. International Myeloma Working Group updated criteria for the diagnosis of multiple myeloma. Lancet. 2014;15:e538-48.

11. Larsen JT, Kumar SK, Dispenzieri A, Kyle RA, Katzmann JA, Rajkumar SV Serum free light chain ratio as a biomarker for highrisk smoldering multiple myeloma. Leukemia. 2013;27:941-6

\title{
Proteomic and genomic integration identifies kinase and differentiation determinants of kinase inhibitor sensitivity in leukemia cells
}

\author{
Pedro Casado ${ }^{1}{ }^{1}$ - Edmund H. Wilkes ${ }^{1}$ - Farideh Miraki-Moud ${ }^{2}$ - Marym Mohammad Hadi ${ }^{1}$ - Ana Rio-Machin ${ }^{3}$. \\ Vinothini Rajeeve ${ }^{1} \cdot$ Rebecca Pike $^{4}{ }^{4}$. Sameena Iqbal $\left.\right|^{5} \cdot$ Santiago Marfa ${ }^{1} \cdot$ Nicholas Lea $^{6} \cdot$ Steven Best $^{6}$. \\ John Gribben ${ }^{2} \cdot$ Jude Fitzgibbon $^{3} \cdot{\text { Pedro R. Cutillas } \mathbb{1}^{1}}^{1}$
}

Received: 17 July 2017 / Revised: 20 November 2017 / Accepted: 24 November 2017 / Published online: 7 April 2018

(c) The Author(s) 2018. This article is published with open access

Kinase inhibitors are efficient in reducing cancer cell viability in cases where malignant cells present a dependency or addiction to the targeted kinase [1]. Genetic alterations can cause constitutive activation of pro-survival and proliferative pathways and often determine the extent by which cancer cells respond to targeted drugs [2,3]. However, other biochemical events, not directly linked to genetic mutations

Electronic supplementary materialThe online version of this article (https://doi.org/10.1038/s41375-018-0032-1) contains supplementary material, which is available to authorized users.

Pedro R. Cutillas

p.cutillas@qmul.ac.uk

1 Cell Signalling \& Proteomics Group, Centre for HaematoOncology, Barts Cancer Institute, Queen Mary University of London, London, UK

2 Cancer Immunology Group, Centre for Haemato-Oncology, Barts Cancer Institute, Queen Mary University of London, London, UK may also contribute to the modulation of oncogenic kinase activity and thus influence responses to kinase targeted drugs $[4,5]$. Here, we integrated drug sensitivity, proteomic, phosphoproteomic, immunophenotypic, and genomic analyses of primary AML to rationalize responses and identify determinants of sensitivity of AML cells to targeted compounds of clinical and preclinical interest in this disease.

We investigated the effects on cell viability of inhibitors for the kinases FLT3/PKC (midostaurin), PAK (PF3758309), CK2 (silmitasertib), MEK (trametinib), and P38 (TAK-715). Hereafter named as FLT3/PKCi, PAKi, CK2i,

3 Precision Medicine Group, Centre for Haemato-Oncology, Barts Cancer Institute, Queen Mary University of London, London, UK

4 Flow Cytometry Core Facility, Barts Cancer Institute, Queen Mary University of London, London, UK

5 Tissue Bank, Barts Cancer Institute, Queen Mary University of London, London, UK

6 Department of Haematological Medicine, King's College London School of Medicine, London, UK 
Fig. 1 Association of differentiation, kinase activity, and sensitivity to kinase inhibitors in primary AML. a Sensitivity to MEKi as a function of FAB group. $\mathbf{b}$ CD expression across 30 cases and estimation of individual kinase activities in CDs+ and CDsgroups. c Sensitivity to kinase inhibitors as a function of $\mathrm{CD}$ pattern expression. Significance was assessed by Mann-Whitney test in $\mathbf{a}, \mathbf{c}$ and with a z-test in $\mathbf{b}$

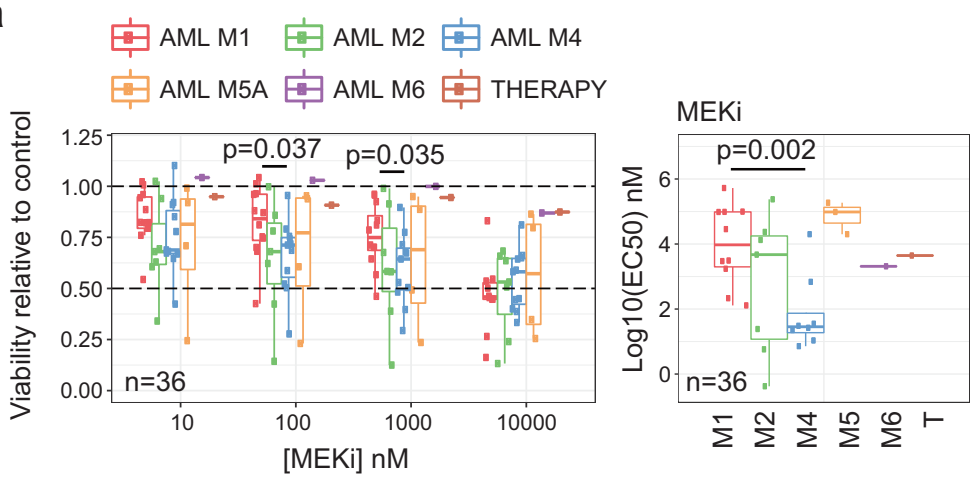

b

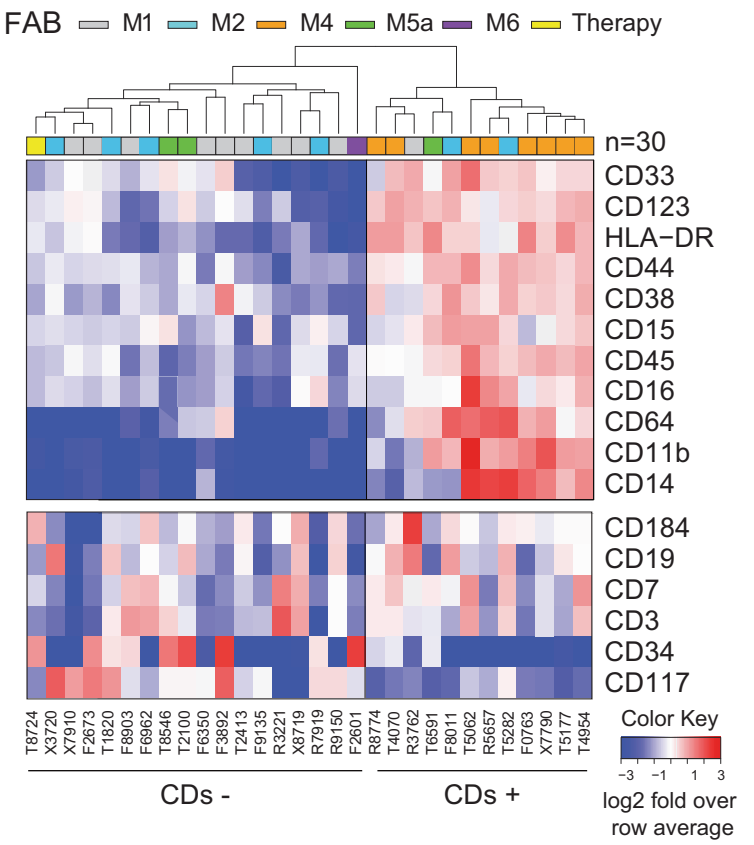

KSEA score CDs+ / CDs-

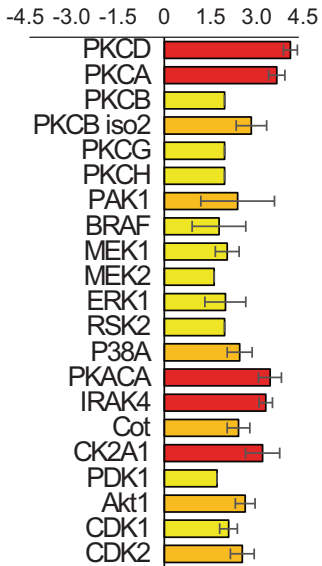

$\square p<0.05$

$\square p<0.01$

$\square p<0.001$

$\mathrm{n}=30$
C
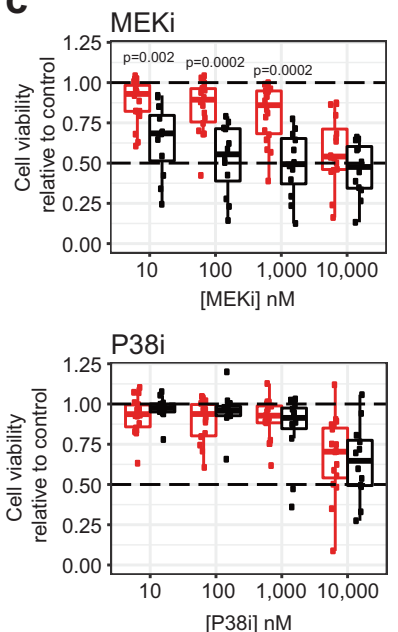
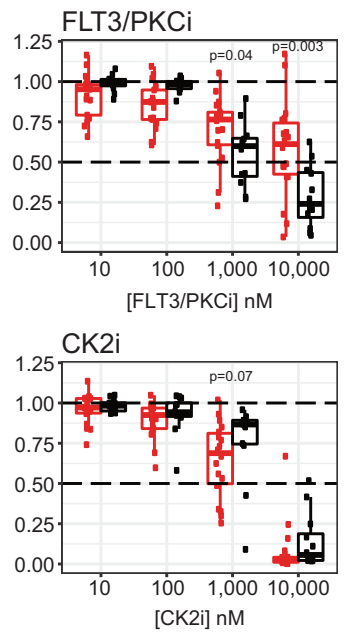

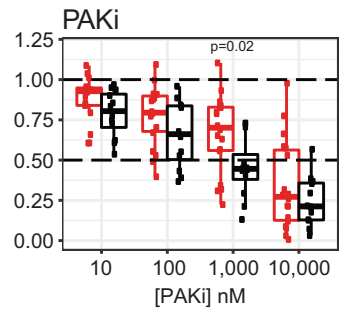

툴D-

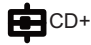

$n=30$
MEKi, and P38i, respectively. Dose-response curves for cells obtained from 36 AML patients (Data File S1) showed heterogeneous responses to all compounds (Figure S1). However, samples of the M4 FAB subtype were on average more sensitive than M1 samples to MEKi (Fig. 1a).

Based on the surface expression of a set of co-expressed CD markers (Figure S2a), mass cytometry data subdivided our 
patient samples into two groups (Fig. 1b (heatmap)). These analyses could be performed in 30 cases with sufficient number of cells and produced two main groups, which we termed CDs+ and CDs-, consisting of 12 and 18 patients, respectively. Untargeted mass spectrometry proteomics (Data File S2) uncovered greater expression in the $\mathrm{CDs}+$ group relative to $\mathrm{CDs}$ - of a set of proteins linked to differentiation, several kinases, and other signal-transduction regulators (Figure S2b, c). Global phosphoproteomics by mass spectrometry showed that CDs+ cells had an increase in protein phosphorylation relative to the CDs - cases (Figure S2d, Data File S3) and activated kinases downstream growth factor signaling, as illustrated by kinase substrate enrichment analysis [6] (Fig. 1b (bar plot)). In addition, individual phosphorylation markers [7] on ERK1/2 (MAPK3/1), PAK1/2, MEK1 (MAP2K1), and PKCס (PRKCD) were highly phosphorylated in the CDs+ group (Figure S2d) and correlated with the surface expression of individual $\mathrm{CD}$ markers linked to differentiation (Figure S3a and S3b).

Since CDs + cases activated kinase survival pathways to a greater extent than CDs- cases, we reasoned that cells from these groups would respond differently to kinase inhibitors. Consistently with this hypothesis, cell viability analysis as a function of treatment with kinase inhibitors showed that CDs + cases were more sensitive than CDs - to MEKi (at 10, 100, and $1000 \mathrm{nM}$ ), FLT3/PKCi (1 and 10 $\mu \mathrm{M})$, and PAKi $(1 \mu \mathrm{M})$ (Fig. 1c). These concentrations are physiologically relevant for MEKi and FLT3/PKCi $[8,9]$. Together, our results suggest that CDs + cells had higher expression of proteins associated with myelomonocytic differentiation and kinase signaling relative to negative cells, and consequently showed high phosphorylation and activation of pro-survival kinases, which was translated into an increased sensitivity to treatments with PAKi, midostaurin, and trametinib.

In order to rationalize drug responses with greater detail, we sequenced 25 genes frequently mutated in AML in 27 cases of our cohort (Data File S4, sequencing failed in three samples). We found that genes involved in kinase signaling (NRAS, $B R A F$, and FLT3), were more frequently mutated in CDs+ cases (Figure S4, $p=0.008$ by hypergeometric test). We performed an integrative and systematic analysis of mutational profiles with the mass spectrometry and cytometry data. Cells positive for NRAS mutations, high MAPK1 phosphorylation, or the CDs+ phenotype were more sensitive to MEKi than negative cells (Fig. 2a (i-iv)). Cells with the NRAS/BRAF/ FLT3-ITD genotypes were not more sensitive to MEKi than cells with just either NRAS or BRAF mutations (Fig. 2a (v)). In contrast, cases positive for NRAS, BRAF mutations or the CDs + phenotype (NRAS/BRAF/CDs+) were on average more sensitive to MEKi than cells without this molecular signature (Fig. 2a (vi-ix)). The $p$ value assessment for the comparisons showed that the NRAS/BRAF/CDs+ signature produced the most significant difference followed by the NRAS/BRAF/p-
MAPK1hi/CDs + signature (Fig. 2 (bar plot)). Our results suggest that, in addition to $N R A S / B R A F$ activating mutations, the RAS/MEK/ERK pathway may be activated by other means in cells with high expression of CD markers. Thus, MEKi treatment was more likely to reduce AML cell viability in cases positive for at least one of these markers (NRAS/ BRAF mutations or specific CD pattern expression).

Although 15 cases with the NRAS/BRAF/CDs + signature were on average more sensitive to MEKi than negative cases, 8 of such cases were resistant (viability $>50 \%$ ) to treatment (Fig. 2a (viii)). Within these 15 cases positive for NRAS/ $B R A F / C D s+$, cells with FLT3-ITD mutations were significantly more resistant to MEKi than cells without this mutation ( $p=0.012$, Fig. $2 b$ ). Several phosphorylation markers were also found to be associated with responses to MEKi within the NRAS/BRAF/CDs+ cases, including STAT5A ${ }^{\mathrm{S} 780}$, STAT5A $^{\mathrm{S} 128}$, TOP2A $\mathrm{A}^{\mathrm{S} 1213}, \mathrm{KDM}^{\mathrm{S}} \mathrm{C}^{\mathrm{S} 317}$, and CAMKK1 ${ }^{\mathrm{S} 458}$ (Fig. 2b). When the whole cohort of 27 patients was considered, samples positive for $N R A S / B R A F / C D s+$ and negative for FLT3-ITD or low pSTAT5A or pKDM5C were more sensitive to MEKi than the other cells (Fig. 2d, Figure S5a). This higher sensitivity of $N R A S / B R A F / C D s+$ cases that were FLT3-ITD negative or pKDM5C $\mathrm{C}^{\mathrm{S} 317}$ low was consistent across several MEKi concentrations (Figure S5a).

Our results suggest two distinct mechanisms of intrinsic resistance to MEK inhibition. One occurs in cells that are not addicted to the pro-survival actions of MEK because these have low RAS/MEK/ERK pathway activity. The other occurs in cells which, albeit having a highly active RAS/ MEK/ERK, bypass MEK inhibition using the FLT3/STAT5 axis; a pathway known to sustain AML viability and proliferation by acting in parallel to RAS/MEK/ERK signaling $[10,11]$. Pemovska et al. [12] also observed a high response to trametinib in a subgroup of AML primary cells. NRAS is frequently mutated in AML and in a recent clinical trial $\sim 20 \%$ of AML patients positive for NRAS or KRAS mutations responded to trametinib [13]. Our results suggest that selection of patients for therapy based not only on NRAS/ KRAS mutations but also on direct markers of MEK activity, and STAT5 and KDM5A phosphorylation may increase the proportion of patients that will respond to this treatment.

We also noted that FLT3-ITD status was not associated with the responses of cells to FLT3/PKCi (Fig. 2c, Figure $\mathrm{S} 5 \mathrm{~b}$ ), an inhibitor recently approved to treat FLT3 mutant AML [14]. In contrast, CD expression and phosphorylation markers on PKC $\delta$ and on its substrate GSK3A [15] were increased in FLT3/PKCi-sensitive cells at $10 \mu \mathrm{M}$ and $1 \mu \mathrm{M}$ (Fig. 2c, Figure S5b). Our results suggest that the mode of action of midostaurin may involve the inhibition of PKC 8 (a known target of this drug), which we found activated in primary AML (Fig. 1b, Figure S4a).

In conclusion, we found that AML cells remodel their kinase-signaling network during differentiation, resulting in a 

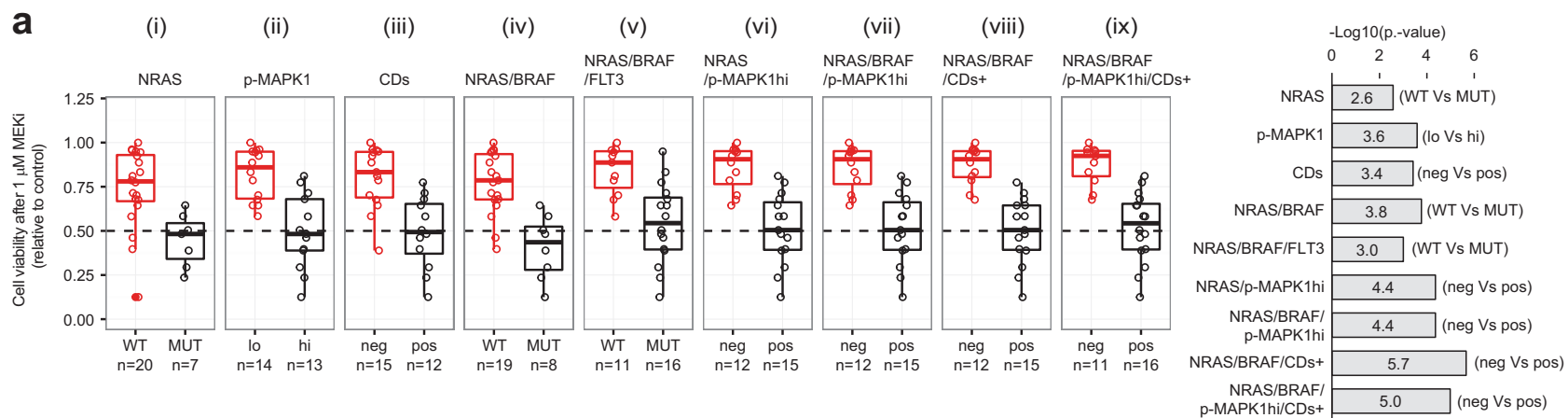

b

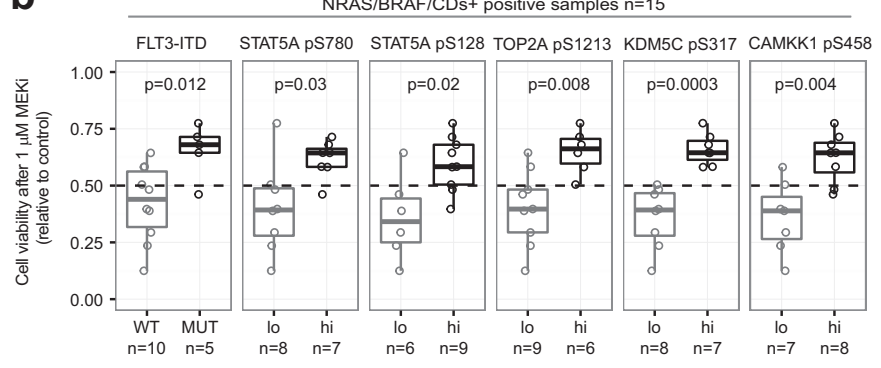

All samples $n=27$

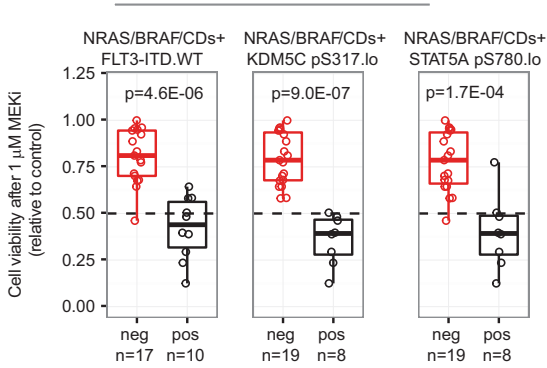

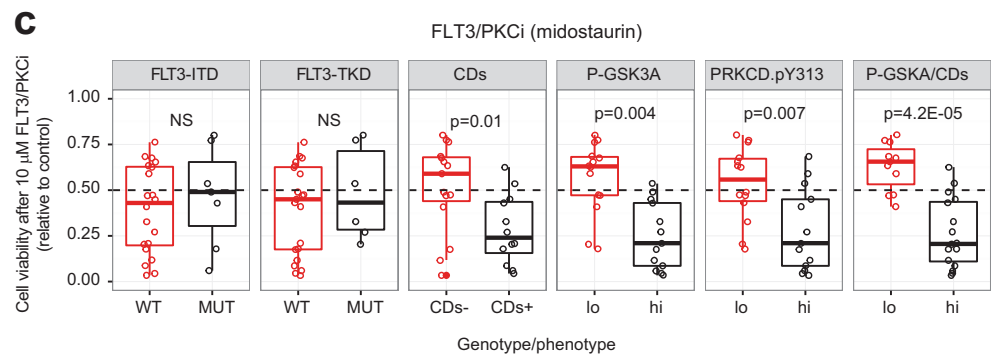

Fig. 2 Integration of genomic, phosphoproteomics, and mass cytometry data to rationalize kinase inhibitors sensitivity. a Viability of AML cells within the indicated genotype/phenotype groups after treatment with MEKi. b Sensitivity of NRAS/BRAF/CDs + positive cells to MEKi as a function of the indicated factors. c FLT3/PKCi

marked increase in the activity of pro-survival pathways regulated by MEK and PKC. Specific combinations of target and parallel kinase-pathway activation (caused by genetic and non-genetic events) determined the extent by which AML cells respond to treatments with trametinib or midostaurin.

Acknowledgements We thank Steve Lim, Marilyn Salvat-Lago, and Lara Painter for technical support, Janet Mathews for clinical data, and Maruan Hijazi for manuscript reading.

Funding Barts and The London Charity (297/2249), CRUK (C16420/ A18066), and BBSRC (BB/M006174/1).

\section{Compliance with ethical standards}

Conflict of interest The authors declare that they have no conflict of interest.

Open Access This article is licensed under a Creative Commons Attribution 4.0 International License, which permits use, sharing, adaptation, distribution and reproduction in any medium or format, as sensitivity of AML cells with the indicated phenotype/genotype. Phosphorylations are denoted as (hi) and (lo) based on a greater or lower phosphorylation than the median across all cases. Significance was assessed by Mann-Whitney test

long as you give appropriate credit to the original author(s) and the source, provide a link to the Creative Commons license, and indicate if changes were made. The images or other third party material in this article are included in the article's Creative Commons license, unless indicated otherwise in a credit line to the material. If material is not included in the article's Creative Commons license and your intended use is not permitted by statutory regulation or exceeds the permitted use, you will need to obtain permission directly from the copyright holder. To view a copy of this license, visit http://creativecommons. org/licenses/by/4.0/.

\section{References}

1. Workman P, Al-Lazikani B, Clarke PA. Genome-based cancer therapeutics: targets, kinase drug resistance and future strategies for precision oncology. Curr Opin Pharmacol. 2013;13:486-96.

2. Papaemmanuil E, Gerstung M, Bullinger L, Gaidzik VI, Paschka $\mathrm{P}$, Roberts ND, et al. Genomic classification and prognosis in acute myeloid leukemia. N Engl J Med. 2016;374:2209-21.

3. Cancer Genome Atlas Research Network, et al. Genomic and epigenomic landscapes of adult de novo acute myeloid leukemia. N Engl J Med. 2013;368:2059-74. 
4. Lemmon MA, Schlessinger J. Cell signaling by receptor tyrosine kinases. Cell. 2010;141:1117-34.

5. Straussman R, Morikawa T, Shee K, Barzily-Rokni M, Qian ZR, $\mathrm{Du} J$, et al. Tumour micro-environment elicits innate resistance to RAF inhibitors through HGF secretion. Nature. 2012;487:500-4.

6. Casado P, Rodriguez-Prados JC, Cosulich SC, Guichard S, Vanhaesebroeck B, Joel S, et al. Kinase-substrate enrichment analysis provides insights into the heterogeneity of signaling pathway activation in leukemia cells. Sci Signal. 2013;6:rs6.

7. Wilkes EH, Terfve C, Gribben JG, Saez-Rodriguez J, Cutillas PR. Empirical inference of circuitry and plasticity in a kinase signaling network. Proc Natl Acad Sci USA. 2015;112:7719-24.

8. Wang Y, Yin OQ, Graf P, Kisicki JC, Schran H. Dose- and timedependent pharmacokinetics of midostaurin in patients with diabetes mellitus. J Clin Pharmacol. 2008;48:763-75.

9. Leonowens C, Pendry C, Bauman J, Young GC, Ho M, Henriquez $\mathrm{F}$, et al. Concomitant oral and intravenous pharmacokinetics of trametinib, a MEK inhibitor, in subjects with solid tumours. Br J Clin Pharmacol. 2014;78:524-32.

10. Mizuki M, Fenski R, Halfter H, Matsumura I, Schmidt R, Muller $\mathrm{C}$, et al. Flt3 mutations from patients with acute myeloid leukemia induce transformation of $32 \mathrm{D}$ cells mediated by the Ras and STAT5 pathways. Blood. 2000;96:3907-14.
11. Hayakawa F, Towatari M, Kiyoi H, Tanimoto M, Kitamura T, Saito H, et al. Tandem-duplicated Flt3 constitutively activates STAT5 and MAP kinase and introduces autonomous cell growth in IL-3-dependent cell lines. Oncogene. 2000;19:624-31.

12. Pemovska T, Kontro M, Yadav B, Edgren H, Eldfors S, Szwajda A, et al. Individualized systems medicine strategy to tailor treatments for patients with chemorefractory acute myeloid leukemia. Cancer Discov. 2013;3:1416-29.

13. Borthakur G, Popplewell L, Boyiadzis M, Foran J, Platzbecker U, Vey N, et al. Activity of the oral mitogen-activated protein kinase kinase inhibitor trametinib in RAS-mutant relapsed or refractory myeloid malignancies. Cancer. 2016;122:1871-9.

14. Stone RM, Mandrekar SJ, Sanford BL, Laumann K, Geyer S, Bloomfield CD, et al. Midostaurin plus chemotherapy for acute myeloid leukemia with a FLT3 mutation. $N$ Engl J Med. 2017;377:454-64.

15. Fang X, Yu S, Tanyi JL, Lu Y, Woodgett JR, Mills GB. Convergence of multiple signaling cascades at glycogen synthase kinase 3: Edg receptor-mediated phosphorylation and inactivation by lysophosphatidic acid through a protein kinase C-dependent intracellular pathway. Mol Cell Biol. 2002;22:2099-110.

\title{
Whole-exome sequencing reveals acquisition of mutations leading to the onset of donor cell leukemia after hematopoietic transplantation: a model of leukemogenesis
}

\author{
Julia Suárez-González ${ }^{1,2}$ - Carolina Martínez-Laperche ${ }^{2,3} \cdot$ Nerea Martínez $^{4} \cdot$ Gabriela Rodríguez-Macías $^{3}$. \\ Mi Kwon ${ }^{2,3} \cdot$ Pascual Balsalobre ${ }^{2,3} \cdot$ Diego Carbonell $\mathbb{1}^{2,3} \cdot$ María Chicano $^{2,3} \cdot$ David Serrano $^{2,3} \cdot$ Juan Carlos Triviño ${ }^{5}$. \\ Miguel Ángel Piris ${ }^{6} \cdot$ Jorge Gayoso ${ }^{2,3} \cdot$ José Luis Díez-Martín ${ }^{2,3,7} \cdot$ Ismael Buño $^{1,2,3}$
}

Received: 31 July 2017 / Revised: 17 November 2017 / Accepted: 30 November 2017 / Published online: 5 February 2018

(C) Macmillan Publishers Limited, part of Springer Nature 2018

These authors contributed equally: Julia Suárez-González, Carolina Martínez-Laperche.

Electronic supplementary materialThe online version of this article (https://doi.org/10.1038/s41375-018-0042-z) contains supplementary material, which is available to authorized users.

Carolina Martínez-Laperche cmlaperchehgugm@gmail.com

1 Genomics Unit, Gregorio Marañón General University Hospital, Gregorio Marañón Health Research Institute (IiSGM), Madrid, Spain

2 Gregorio Marañón Health Research Institute (IiSGM), Madrid, Spain

3 Department of Hematology, Gregorio Marañón General University
Allogeneic hematopoietic stem cell transplantation (alloSCT) is an effective treatment for hematologic malignancies. The most frequent cause of post-transplant mortality is disease relapse, the majority of the cases present recurrence of original disease from outgrowth of residual cells having

Hospital, Madrid, Spain

Cancer Genomics, IDIVAL, Santander, Spain

5 Sistemas Genómicos, Valencia, Spain

6 Department of Pathology, Fundación Jiménez Díaz, Centro de Investigación Biomédica en Red de Cáncer (CIBERONC), Madrid, Spain

7 Department of Medicine, School of Medicine, Complutense University of Madrid, Madrid, Spain 